\title{
Homeopathic Clinical Features of 18 Patients in COVID-19 Outbreaks in Hong Kong
}

\author{
Ka Lun Aaron To ${ }^{1}$ Yuen Ying Yvonne Fok ${ }^{1}$ (1) \\ ${ }^{1}$ Hong Kong Association of Homeopathy, Hong Kong \\ Homeopathy 2020;109:146-162.
}

\begin{abstract}
Address for correspondence Yuen Ying Yvonne Fok, MB ChB, MSc Epidemiology and Biostatistics, Hong Kong Association of Homeopathy, 4/F, Union Park Center, No. 771-775 Nathan Road, Prince Edward, Hong Kong (e-mail: yvonne.fok@chinesehomeopathy.com).
\end{abstract}

\begin{abstract}
Background Hong Kong is geographically located in the province of Guangdong which, after Hubei, has been the region of China second-most affected by the COVID-19 pandemic. Compared to the pathognomonic symptoms of the named disease, homeopathic symptoms are always more helpful for homeopathic prescriptions.

Aim This study reports and summarizes the homeopathic symptoms observed in 18 confirmed/suspected epidemiologically related cases in cluster outbreaks of COVID-19 in Hong Kong in early 2020.

Methods Homeopathic symptoms from this case series were collected from 18 consecutive patients who, in addition to their concurrent conventional treatment or traditional Chinese medicine, actively sought help from homeopathy as an adjunctive measure for symptomatic relief from COVID-19. Cases were categorized according to outbreak clusters, focusing mainly on the homeopathic symptoms. In the analysis, frequency of all homeopathic medicines, common rubrics in all the cases, common rubrics in each of the top-ranked remedies, and differentiating symptoms for each topranked remedy were determined.

Results Homeopathic symptoms of 18 cases, each identified as mild and belonging to one of six separate clusters, are reported. Eighteen common symptoms screened out of

Keywords

- homeopathy

- COVID-19

- Hong Kong

- China

- clinical features 79 selected rubrics constituted two sets of homeopathic symptom pictures: Bryonia alba $(n=4)$ and Gelsemium sempervirens $(n=12)$. Eight and seven differentiating features, respectively, were identified for Bryonia alba and Gelsemium sempervirens. Conclusion The common symptoms of 18 mild COVID-19 cases constituted two sets of homeopathic symptom pictures, indicating Bryonia alba or Gelsemium sempervirens; they were indicated in 4 and 12 cases, respectively, out of the 18 in total.
\end{abstract}

\section{Introduction}

According to the data available on April 8, 2020, the coronavirus disease 2019 (COVID-19) has affected at least 209 countries, with more than $1,350,000$ reported cases and 79,000 deaths. ${ }^{1}$ The World Health Organization (WHO) officially declared the coronavirus a "pandemic" on March 11,2020 . An epidemic is the unexpectedly high incidence of a disease in a community or region during a given time period;

received

March 31, 2020

accepted after revision

April 19, 2020

published online

June 5, 2020 10.1055/s-0040-1710545. ISSN $1475-4916$. it becomes a pandemic when it affects an even wider geographical area. Health care systems in developed countries-not to mention the developing countries-have been challenged by the overwhelming number of patients.

Up to April 8, 2020, there were more than 81,000 cases and 3,300 deaths in China from the COVID-19 pandemic. ${ }^{2}$ Hong Kong is geographically located in Guangdong (formerly Canton), the second-most affected province in China after Hubei. It has become one of the most affected cities in China
Copyright @ $\odot 2020$ The Faculty of Homeopathy
License terms

()(1) $\Theta \circledast$ 
since the second wave of the epidemic there. With the influx of imported cases from other countries, more than 950 confirmed cases were reported in Hong Kong by April 8, about 10 -fold the number of cases resulting from the first wave in late February 2020.

The WHO traditional medicine (TM) Strategy 2014 to $2023^{3}$ was developed and aimed to "support Member States in developing proactive policies and implementing action plans that will strengthen the role TM plays in keeping populations healthy". Traditional Chinese Medicine (TCM) played an important role in the COVID 2019 treatment protocol in China. On February 17, 2020, the National Health Commission (NHC) of the People's Republic of China reported that $85 \%$ of confirmed COVID-19 patients had been treated with TCM. ${ }^{4}$ A recent systematic review showed that, based on the evidence from SARS and H1N1 influenza prevention, TCM could be an alternative approach for the prevention of COVID-19 in high-risk populations. ${ }^{5}$

In January 2019, at the World Integrated Medicine Forum in Goa, India, Dr. Geetha Krishnan G. Pillai, representative from the Traditional, Complementary and Integrative Medicine Unit of WHO, stated: "Even today, for millions of people across the globe, Traditional Medicine is their first line of medical care, and in many communities the only one. Considering this fact, it is highly essential to build an integrated health care model which uses the strengths of TM alongside the advances in modern medical technologies. It is necessary to re-think the strategies and policies of nations who try to achieve the Universal Health Coverage (UHC) goal by only relying on investments made on hugely infrastructure-driven, highly cost-intensive, health care services. It is high time to think of using the TM knowledge, which is community based, low cost, and socially acceptable, with its health preservation-based approaches, for supporting the achievement of UHC goals".

As a TM in Europe and many other countries worldwide, homeopathy was used in history ${ }^{6}$ during the epidemics of scarlet fever, ${ }^{7}$ Spanish influenza, ${ }^{8}$ Chikungunya fever, ${ }^{9,10}$ dengue fever, ${ }^{11,12}$ leptospirosis, ${ }^{13}$ and malaria, ${ }^{14}$ for example. Given the paucity of strongly evidence-based regimens for conventional vaccines and anti-viral medication in the current COVID-19 pandemic, homeopathy has been used, respectively, by $4-5 \%$ and $45-50 \%$ of the populations in Hong Kong and its adjacent city, Macau; it has been used as an adjunctive measure in the management of influenza-like diseases alongside conventional medicine or TCM.

According to the Organon by Samuel Hahnemann, every epidemic should be treated as if it were something "new and unknown"(\$100). A homeopathic practitioner "does not immediately perceive the complete picture of the epidemic in the first case that he treats" ( $§ 101)$ : we must closely observe series of cases "since each collective disease reveals itself in the totality of its signs and symptoms" $(\S 101)$. Characteristic symptoms that are peculiar to the epidemic are important elements for the totality of a symptom picture (§102). Instead of helping an individual to boost up his or her self-healing power, we should aim at treating the whole epidemic region as one patient: that is, the whole "energy pattern" can only be revealed by different patients with the same disease but different constitutions. By identifying the peculiar and uniform characteristics for most patients in the same outbreak, we can identify one or several remedies that are most consistently serviceable in the epidemic for people with good past health (\$241). In different epidemic areas, there are differences in weather, diet, collective emotional status, strains of virus, etc., and therefore the named disease may present itself with different symptomatology in different regions, which will require different homeopathic medicines. Besides, within a given population affected by the same virus, we will probably see distinct sets of symptoms, which will indicate the need for different medicines.

Compared to the pathognomonic symptoms of the disease, homeopathic symptoms are more helpful for homeopathic prescriptions. The objective of this case series is to report and share the sets of homeopathic symptoms identified in 18 symptomatic COVID-19 patients in Hong Kong who used homeopathy as adjunctive care for symptom relief. It is not the intention of the authors to suggest homeopathic prescription guidelines for COVID-19 symptoms because of the likely variation in symptomatology in different countries and the limitations of our available data.

\section{Methods}

Considering the limited availability and the considerable falsenegative rate of diagnostic tools, especially at the earlier stage of the outbreak, and with reference to the diagnostic criteria in the 7th edition of the diagnosis and treatment protocol in China, ${ }^{15}$ consecutive patients were included only if they had fulfilled at least one of the following criteria:

1. Reverse transcription polymerase chain reaction (RT-PCR) positive for 2019-novel Coronavirus (2019-nCoV);

2. Serology test positive for $\operatorname{IgM} / \operatorname{IgG}$ (immunoglobulin $\mathrm{M} /$ immunoglobulin G) specific for COVID-19;

3. Presenting with fever, chills, or respiratory symptoms, and related to an outbreak cluster.

A cluster is defined as three or more symptomatic patients identifiable in a 2-week period in a small unit such as family, office, or school class-that is, each cluster will have arisen from an epidemiologically related index case-and with one or more cases being RT-PCR positive.

Categorization of severity was as follows under the treatment protocol in China:

1. Mild: fever or respiratory symptoms without pneumonia features on imaging.

2. Moderate: fever or respiratory symptoms, with pneumonia features on imaging.

3. Severe: respiratory rate $>30$ per minute, or oxygen saturation $\leq 93 \%$ at rest.

4. Critical: respiratory failure with mechanical ventilation support, or shock or organ failure requiring intensive care.

All the patients actively sought adjunctive care from homeopathy. All except one (Case HK6.1) used homeopathy 
in addition to their concurrent conventional or TCM treatment. All except one suspected case (HK6.1) were consulted through telephone calls or video calls. Patients were requested to fill in an electronic patient registration form when they made appointments for suspected COVID-19 symptoms, and the consultation would then be offered for free through video calls. In the case of a patient with fever/ respiratory symptoms who walked into the consulting rooms without making an appointment, personal protective equipment based on droplet and contact precaution was provided to the staff. If a case was diagnosed as COVID-19 before they sought help from homeopathy, distant consultation and follow-up were done by video or audio calls during their quarantined period. If a case was suspected to be COVID-19 when they sought help from homeopathy, they were advised to follow the most updated instruction of quarantine and treatment from the Hong Kong government.

The 18 case takings were performed by TKL, a homeopathic practitioner with more than 10 years of experience in homeopathic practice. A standard questionnaire on common homeopathic symptoms was filled in by all diagnosed/suspected COVID-19 patients, with or without the help of a consultingroom assistant, before the consultation with author KLAT. Verbal consent to share anonymized clinical information for academic purposes was obtained from each patient.

Cases are presented according to their outbreak cluster, defined as above. The case presentations focused mainly on the homeopathic symptoms. Full repertorizations, with Synthesis Repertory 2009V last updated in RadarOpus 2.2.12, are presented for each individual case.

Homeopathic medicines were delivered to patients within 24 hours after consultation. Follow-up checkpoints for patients were suggested as 12 hours, 24 hours, 3 days, 7 days, and 14 days after the intake of the first dose of medicine. Patients, however, were encouraged to keep contact with the assistants even at time points other than the above. At each checkpoint, patients were asked to give an overall severity rating of their symptoms and general well-being: 100 was the designated "reference" score for a patient in the 24 hours immediately before the first dose of medicine; 0 was the score when all of the patient's symptoms disappeared and general well-being returned to normal (i.e., $100 \%$ improvement of symptoms); 200 was the score when the severity of symptoms and general well-being was twice as bad as before. There was no upper limit of the score, and any percentage score between the above examples was eligible.

In the analysis, frequency of all homeopathic medicines, common symptoms in all the cases, and common rubrics for each of the top-ranked remedies are presented. Differentiating features are also presented.

Besides, differentiating features are also presented, those being defined as rubrics that fulfilled the following criteria:

1. Present in at least $50 \%$ of cases for the top-ranked remedy;

2. Present in no more than 2 cases for other top-ranked remedies.

The article was first written in Chinese and translated by author YYYF into English.

\section{Findings}

The 18 patients were identified in six separate clusters of COVID-19, each cluster comprising $1,1,5,5,5$ and 1 case or cases, respectively.

\section{Cluster no.1}

\section{Case HK1.1}

The patient was a 62-year-old woman, with good past health and repeated close contact in a cluster with more than $10 \mathrm{RT}$ PCR positive cases, diagnosed in February 2020.

She had repeated close contact with the cluster since January 25, 2020, developed bone pain and mild dry cough in early February. The patient's symptoms were categorized as mild, but they gradually worsened without fever for nearly 1 month. They were treated with TCM for 4 weeks; homeopathy was added at the fourth week for persistent symptoms. The patient did not take any conventional medication. An RTPCR test, carried out once after 4 weeks of TCM and 2 days of homeopathy, was negative. The following homeopathic symptoms were found:

1. Slow onset and progression of symptoms.

2. Feeling irritable from the cough; does not want to talk to anyone. Prefers to be alone.

3. Obvious increase in thirst with desire to drink warm water in large quantity.

4. Generally ameliorated after perspiration.

5. Mainly dry cough, with very occasional greenish sputum.

6. Extremely bad pulsating temple headache and middle chest pain aggravated from coughing.

7. Cough aggravated by talking and lying down, and after waking up in the morning.

8. Cough associated with tickling feeling in the throat, ameliorated by warm drinks.

Bryonia alba 30C was prescribed, four times daily. The patient reported more than $60 \%$ improvement in symptoms (i.e., she reported a score of 40 ) after 24 hours, and $80 \%$ improvement on day 3 (score of 20). Repertorization is shown in - Fig. 1.

\section{Cluster no. 2}

\section{Case HK2.1}

The patient was a 21-year-old man, who was confirmed for COVID-19 infection with RT-PCR 2 days after returning from the United Kingdom in March. The patient was categorized as having mild symptoms. His throat symptoms started 10 days before homeopathic consultation. There had been one day of low-grade fever (day 4) after symptoms started, which quickly improved with antipyretics. The antiviral drugs, Kaletra and Ribavirin, were started at day 5. Imaging did not show definite pneumonia, but the cough was progressively worse. The following homeopathic symptoms were found:

1. Slow onset and progression of symptoms.

2. Fever was generally associated with bone pain. 
1. Clipboard 1

1. GENERALS - SLOW MANIFESTATION

2. MIND - COMPANY - aversion to

3. MIND - IRRITABILITY - cough, from

4. GENERALS - PAIN - Bones

5. GENERALS - FOOD AND DRINKS - warm drinks - desire

6. STOMACH - THIRST - large quantities; for

7. HEAD - PAIN - Temples - cough agg.; during

8. THROAT - PAIN - cough - during - agg.

9. COUGH - TALKING - agg.

10. COUGH - LYING - agg.

11. COUGH - TICKLING - Throat; in

12. COUGH - WARM - drinks - amel.

13. HEAD - PAIN - pulsating pain

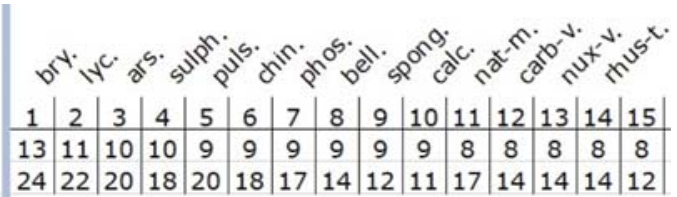

(11) $1 \quad 1$

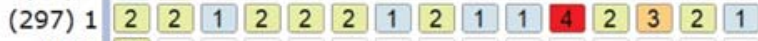

(4) 12

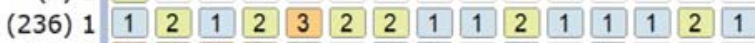

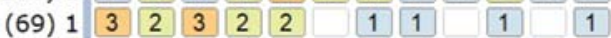

\begin{tabular}{l|l|l|l|l|l|l|l|l|l|l|l|l|l|} 
(88) 1 & 3 & 1 & 3 & 3 & & 2 & 3 & 1 & 1 & 1 & 3 & & \\
\hline
\end{tabular}

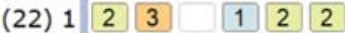

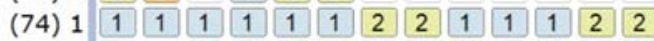

\begin{tabular}{l|l|l|l|l|l|l|l|l|l|l|l|l|l|l|} 
(107) 1 & 1 & 1 & 1 & 1 & 2 & 2 & 2 & 2 & 1 & 1 & 2 & 1 & 1 & 1 \\
\hline
\end{tabular}

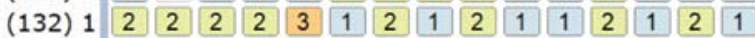

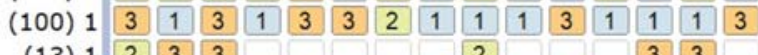

(13) 1233

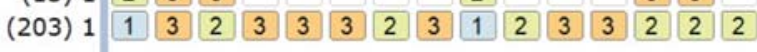

Fig. 1 Repertorization of Case HK1.1.

3. Sudden waking up from sleep every night since the onset of the disease.

4. Obvious increase in thirst, with desire to drink warm water in large quantity.

5. Stitching pain in the throat.

6. Cough was associated with headache, throat pain, and abdominal muscle pain.

7. Headache was aggravated with any motion, even movement of the eyes.

8. Cough was associated with nausea.

9. Cough aggravated during night, especially close to midnight.

10. Cough was associated with tickling feeling in the throat, ameliorated by warm food, warm drink and open air.

11. Rhinitis with loss of smell and taste.

12 . Heavily coated tongue (yellowish-white).

Bryonia alba 30C was prescribed, four times daily. The patient reported that, after the first dose before sleep, it was the first night since the onset of disease that he could sleep through the night without a sudden waking up. More than $70 \%$ of symptoms improved (score of 30 ) after 24 hours, and more than $95 \%$ improved (score of 5 ) at day 3. Repertorization is shown in - Fig. 2 .

\section{Cluster no. 3}

\section{Case HK3.1}

The patient was an 18-year-old woman, with good past health. She was suspected to be a COVID-19 case, and serology for the disease was positive when it was available 7 days after adjunctive homeopathic treatment. She was categorized as a mild case.

Mild symptoms started in February 2020, around a week after contact with the index case. Symptoms gradually worsened after 2 weeks. The patient was treated with TCM for around 3 weeks, without much improvement in symptoms, before she sought help from homeopathy. She had subjectively assessed

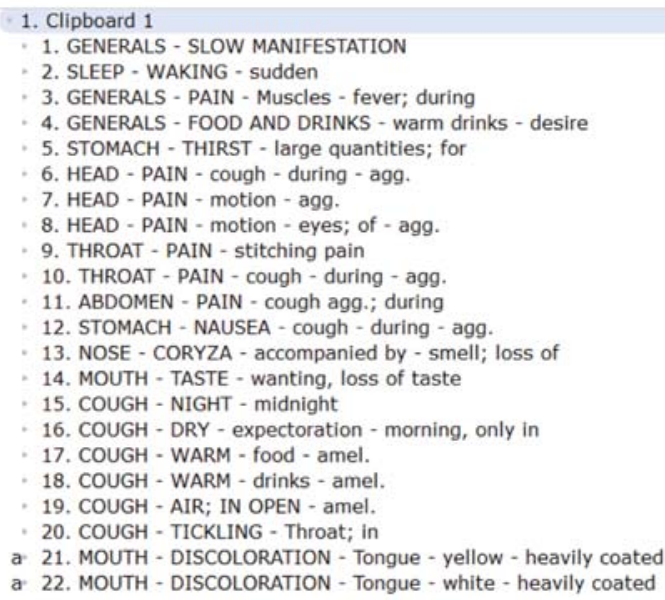

Fig. 2 Repertorization of Case HK2.1. 
shortness of breath with normal respiratory rate at consultation. The following homeopathic symptoms were found:

1. Slow onset and progression of symptoms.

2. No fever but chills, with mental stupefaction and weakness during chills.

3. Desire to be alone and not being bothered.

4. General bone pain over the body during chills.

5. General aggravation from wet weather.

6. Obvious increase in thirst, with desire to drink cold water in large quantity.

7. Chills running up and down the back.

8. Chilliness aggravated by motion.

9. Headache starting from nape of the neck, extending to the forehead above the eyes.

10. Difficult to keep eyes open.

11. Headache like a band constricting around the head.

12. Dry cough aggravated during evening, forcing the patient to sit up.

13. Headache aggravated on coughing, causing the patient to hold the head with hands.

14. Headache aggravated from movement of the eyes.

15. Tickling in the throat.

16. Cough associated with involuntary urination.

17. Difficulty in breathing, aggravated during night and by motion.

18. Difficulty in breathing, ameliorated by lying with the head high.

Bryonia alba 30C was prescribed, four times daily. The patient reported to have $20 \%$ improvement (score of 80 ) after 12 hours, and 70\% improvement (score of 30) on the third day. Repertorization is shown in -Fig. $\mathbf{3}$.

\section{Case HK3.2}

The patient was a 21-year-old woman in the same cluster; a serology test, available 1 week after homeopathic treatment, was positive. Her symptoms were categorized as mild. Generalized fatigue and chills began at 4 to 5 days after contact and gradually worsened for more than 3 weeks before she sought help from homeopathy. She had been on TCM treatment. The following homeopathic symptoms were found:

1. Slow onset and progression of symptoms.

2. No fever but prominent chills; chills mainly felt over the back, going up and down.

3. Overwhelming fatigue with mental stupor, feeling drowsy; the patient needed to rest several times during the consultation.

4. Thirstiness before the chills but not during them.

5. General aggravation from wet weather.

6. Generally ameliorated by perspiration.

7. Headache started from nape of the neck extending to the head, like a band constricting around the head.

8. Headache was largely relieved after profuse urination.

9. Cough associated with burning pain in the chest.

10. The cough sounded very hoarse.

11. Tickling in the throat.

12. Cough associated with involuntary urination.

13. Cough ameliorated in open air.

14. Cough aggravated during night.

Gelsemium sempervirens $30 \mathrm{C}$ was prescribed, four times daily. The patient reported $40 \%$ improvement (score of 60 ) after 12 hours, and more than $90 \%$ improvement (score of 10 ) in 3 days. Repertorization is shown in - Fig. 4.

\section{Case HK3.3}

The patient was a 20-year-old woman in the same cluster; a serology test, available 1 week after homeopathic treatment, was positive. Her symptoms were categorized as mild. Generalized fatigue and chills began at around 6 days after the contact; she was on TCM but gradually worsened for

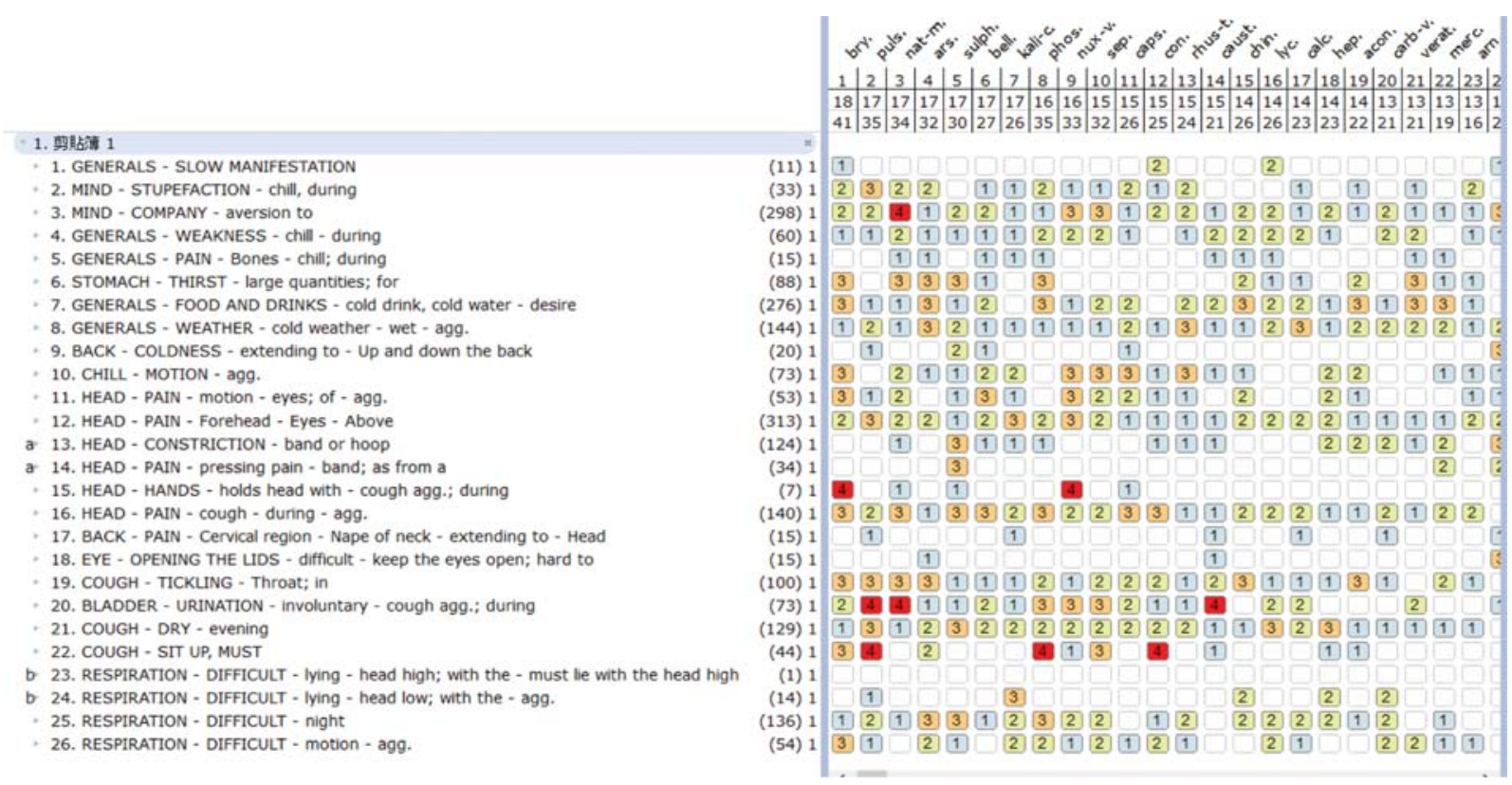

Fig. 3 Repertorization of Case HK3.1. 


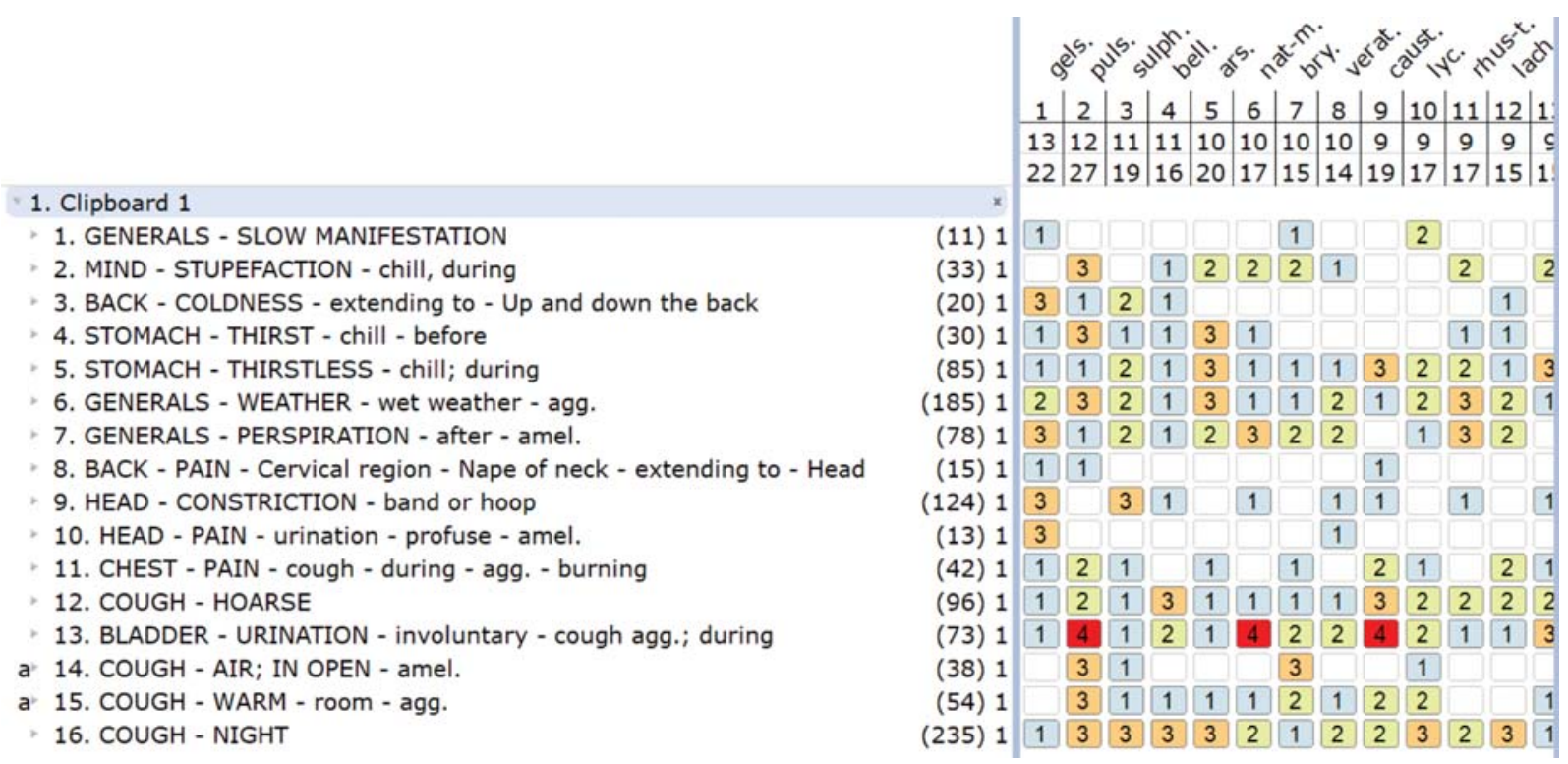

Fig. 4 Repertorization of Case HK3.2.

more than 3 weeks before starting homeopathy. The following homeopathic symptoms were found:

1. Slow onset and progression of symptoms.

2. No fever but prominent chills, which were mainly felt over the back, going up and down.

3. Overwhelming fatigue with mental stupor together with weakness.

4. No thirst during chills.

5. General aggravation from wet weather.

6 . Headache started from the nape of the neck extending to the head, like a band constricting around the head.

7. Headache was largely relieved after profuse urination.

8. A very hard and dry cough.

9. Tickling in the throat.

10. Cough associated with involuntary urination.

11. Cough aggravated during the night.

Gelsemium sempervirens $30 \mathrm{C}$ was prescribed, four times daily. The patient reported $20 \%$ improvement (score of 80 ) at
12 hours follow-up, and was almost symptom free in 3 days. Repertorization is shown in -Fig. $\mathbf{5}$.

\section{Case HK3.4}

The patient was a 19-year-old woman in the same cluster; a serology test, available 1 week after homeopathic treatment, was positive. She was categorized as having mild symptoms. Generalized fatigue and chills began at around 7 days after the contact; she was on TCM for more than 3 weeks before starting homeopathy as the symptoms did not improve. The following homeopathic symptoms were found:

1. Slow onset and progression of symptoms.

2. No fever but prominent chills, which were mainly felt over the back, going up and down.

3. Overwhelming fatigue with mental stupor plus weakness. 4. Heaviness of eyelids; difficulty keeping the eyes open. 5. No thirst during chills.
1. Clipboard 1

1. GENERALS - SLOW MANIFESTATION

2. BACK - COLDNESS - extending to - Up and down the back

3. GENERALS - WEAKNESS - chill - during

4. MIND - STUPEFACTION - chill, during

5. STOMACH - THIRSTLESS - chill; during

6. GENERALS - WEATHER - wet weather - agg.

7. BACK - PAIN - Cervical region - Nape of neck - extending to - Head

8. HEAD - CONSTRICTION - band or hoop

9. HEAD - PAIN - urination - profuse - amel.

10. COUGH - HARD

11. COUGH - NIGHT

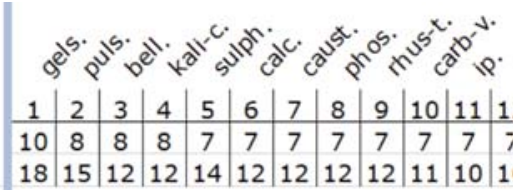

(11) 1

\begin{tabular}{|l|l|l|l|l|l|l|l|l|l|} 
(20) 1 & 3 & 1 & 1 & & 2 & & & & \\
\hline
\end{tabular}

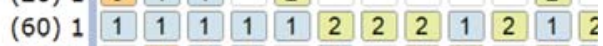

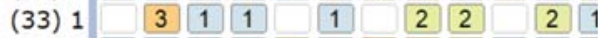

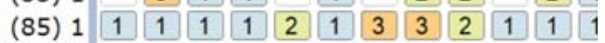

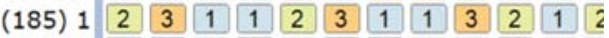

\begin{tabular}{|l|l|l|l|l|l|l|l|l|} 
(15) 1 & 1 & 1 & 1 & 1 & 1 & & 1 \\
\hline
\end{tabular}

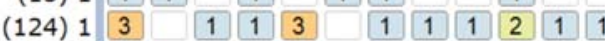

(13) 13

\begin{tabular}{ll|l|l|l|l|l|l|l|l|l|l} 
(75) 1 & 2 & 2 & 3 & 3 & 1 & 1 & 2 & 2 & 1 & 2 \\
\hline
\end{tabular}

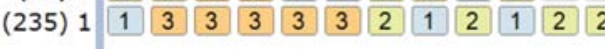

Fig. 5 Repertorization of Case HK3.3. 
1. Clipboard 1

1. GENERALS - SLOW MANIFESTATION

2. BACK - COLDNESS - extending to - Up and down the back

3. GENERALS - WEAKNESS - chill - during

4. MIND - STUPEFACTION - chill, during

5. STOMACH - THIRSTLESS - chill; during

6. GENERALS - WEATHER - wet weather - agg.

7. EYE - OPENING THE LIDS - difficult - keep the eyes open; hard to

8. BACK - PAIN - Cervical region - Nape of neck - extending to - Head

9. HEAD - CONSTRICTION - band or hoop

10. HEAD - PAIN - urination - profuse - amel.

11. COUGH - TICKLING - Throat; in

12. BLADDER - URINATION - involuntary - cough agg.; during

13. COUGH - BARKING

14. COUGH - NIGHT

Fig. 6 Repertorization of Case HK3.4.

6. General aggravation from wet weather.

7. Headache started from the nape of the neck extending to the head, like a band constricting around the head.

8. Headache was largely relieved after profuse urination.

9. The dry cough was barking in quality.

10. Tickling in the throat.

11. Cough associated with involuntary urination.

12. Cough aggravated during the night.

Gelsemium sempervirens 30C was prescribed, four times daily. The patient reported 30\% improvement (score of 70) after 12 hours, and $80 \%$ improvement (score of 20 ) in 3 days. Repertorization is shown in - Fig. 6.

\section{Case HK3.5}

The patient was a 22-year-old woman in the same cluster; a serology test, available 1 week after homeopathic treatment, was positive. The patient's symptoms were categorized as mild. Generalized fatigue and on-and-off low-grade fever with chills began at around 7 days after the contact; she was on TCM for more than 1 week before starting homeopathy. The following homeopathic symptoms were found:

1. Slow onset and progression of symptoms.

2. Fever alternating with chills.

3. Chills mainly felt over the back, going up and down.

4. Overwhelming fatigue with mental stupor plus weakness.

5. Heavy eyelids, with difficulty keeping the eyes open.

6. No thirst during fever and chills.

7. Headache started from the nape of the neck, extending to the head.

8. Headache was largely relieved after profuse urination.

9. Cough was associated with chest pain, burning in quality.

10. Tickling in the throat.

11. Cough associated with involuntary urination.

12. Mainly dry cough, aggravated during night time.
Gelsemium sempervirens 30C was prescribed, four times daily. The patient was afebrile from day 1 after the remedy, and she reported being almost free of symptoms in 3 days. Repertorization is shown in - Fig. $\mathbf{7 .}$

\section{Cluster no. 4}

\section{Case HK4.1}

The patient was a 24-year-old man, with close contact in a cluster having at least one RT-PCR positive case diagnosed in February 2020. A serology test, available 3 weeks after homeopathic treatment was positive. His symptoms were categorized as mild.

He developed generalized fatigue at day 4 after close contact with the index case, worsening for 3 days, and treated with TCM before consultation. The following homeopathic symptoms were found:

1. Low grade fever of around $37.8^{\circ} \mathrm{C}$ for 3 days, with extreme chills; there was no myalgia, thirst, or perspiration.

2. Overwhelming fatigue with mental stupor; heaviness in the body, especially the eyelids.

3. Headache described as "being tied by a band around the head".

4. No feeling of thirst during 3 days of fever.

5. Cough aggravated the headache.

Gelsemium sempervirens $30 \mathrm{C}$ was prescribed, four times daily. The patient reported being afebrile after 36 hours, with $70 \%$ improvement (score of 30 ) in 3 days and symptoms nearly gone at day 5 . Repertorization is shown in -Fig. 8.

\section{Case HK4.2}

The patient was a 27-year-old man in the same cluster, and whose serology test available 3 weeks after homeopathic treatment was positive. The patient was categorized as a mild case. Generalized fatigue began on day 4 after contact, 
1. Clipboard 1

1. GENERALS - SLOW MANIFESTATION

2. GENERALS - WEAKNESS - chill - during

3. MIND - STUPEFACTION - chill, during

4. FEVER - ALTERNATING WITH - chills

5. BACK - COLDNESS - extending to - Up and down the back

6. STOMACH - THIRSTLESS - fever; during

7. STOMACH - THIRSTLESS - chill; during

8. GENERALS - WEATHER - wet weather - agg.

9. EYE - OPENING THE LIDS - difficult - keep the eyes open; hard to

10. BACK - PAIN - Cervical region - Nape of neck - extending to - Head

11. HEAD - PAIN - urination - profuse - amel.

12. COUGH - TICKLING - Throat; in

13. BLADDER - URINATION - involuntary - cough agg.; during

14. CHEST - PAIN - cough - during - agg. - burning

15. COUGH - NIGHT

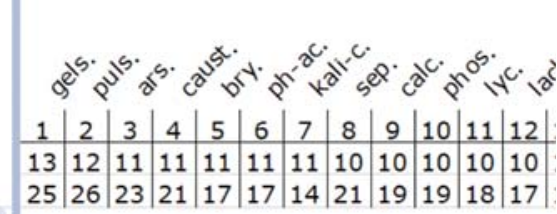

(11) 1

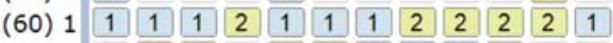

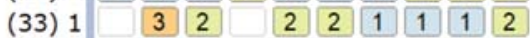

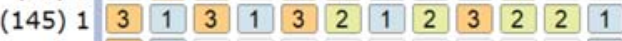

(20) 131

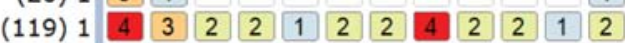

\begin{tabular}{l|l|l|l|l|l|l|l|l|l|l|l|l|} 
(85) 1 & 1 & 1 & 3 & 3 & 1 & 2 & 1 & 1 & 1 & 3 & 2 & 1 \\
\hline
\end{tabular}

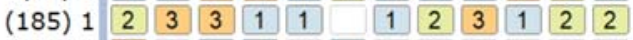

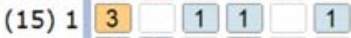

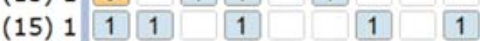

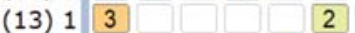

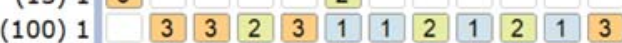

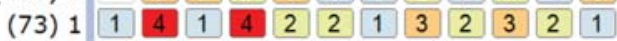

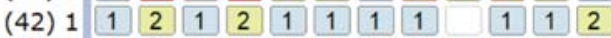

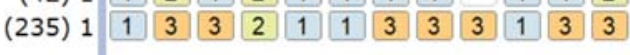

Fig. 7 Repertorization of Case HK3.5.

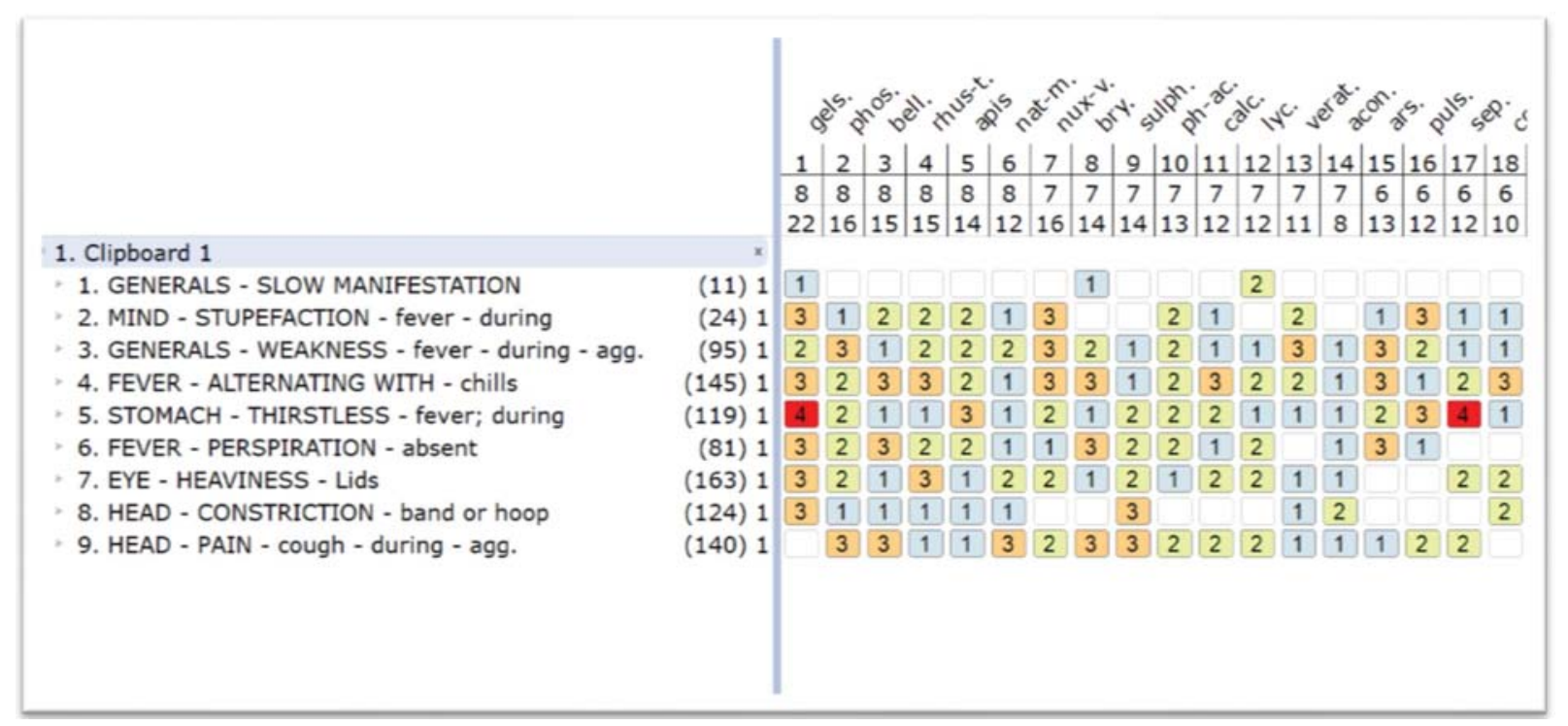

Fig. 8 Repertorization of Case HK4.1.

worsening for 3 days, and treated with TCM before consultation. The following homeopathic symptoms were found:

1. No fever but prominent chills, which were mainly felt over the back first, then in the extremities.

2. Increased thirst, generally ameliorated from perspiration and warmth.

3. Overwhelming fatigue with mental stupor, feeling drowsy and dull (like being drunk) for 3 days.

4. Congestive pain in the forehead, aggravated with coughing. Pain above eyebrows and eyeballs, making it difficult to open the eyes.

5. Cough aggravated the congestive headache.

Gelsemium sempervirens 30C was prescribed, four times daily. The patient reported $30 \%$ improvement (score of 70) at 12 hours, 50\% improvement (score of 50) in 24 hours, and
90\% improvement (score of 10 ) in 3 days. Repertorization is shown in - Fig. 9.

\section{Case HK4.3}

The patient was a 20-year-old woman in the same cluster; a serology test, available 3 weeks after homeopathic treatment, was positive. Symptoms were categorized as mild. Diarrhea and vomiting began at day 4 after close contact with the index case, worsening for 3 days, and treated with TCM with worsening symptoms before consultation. Cough was minimal. The following homeopathic symptoms were found:

1. No obvious fever but prominent chills.

2. Thirsty but could only take small sips of water because of nausea and aggravated symptoms of diarrhea. 


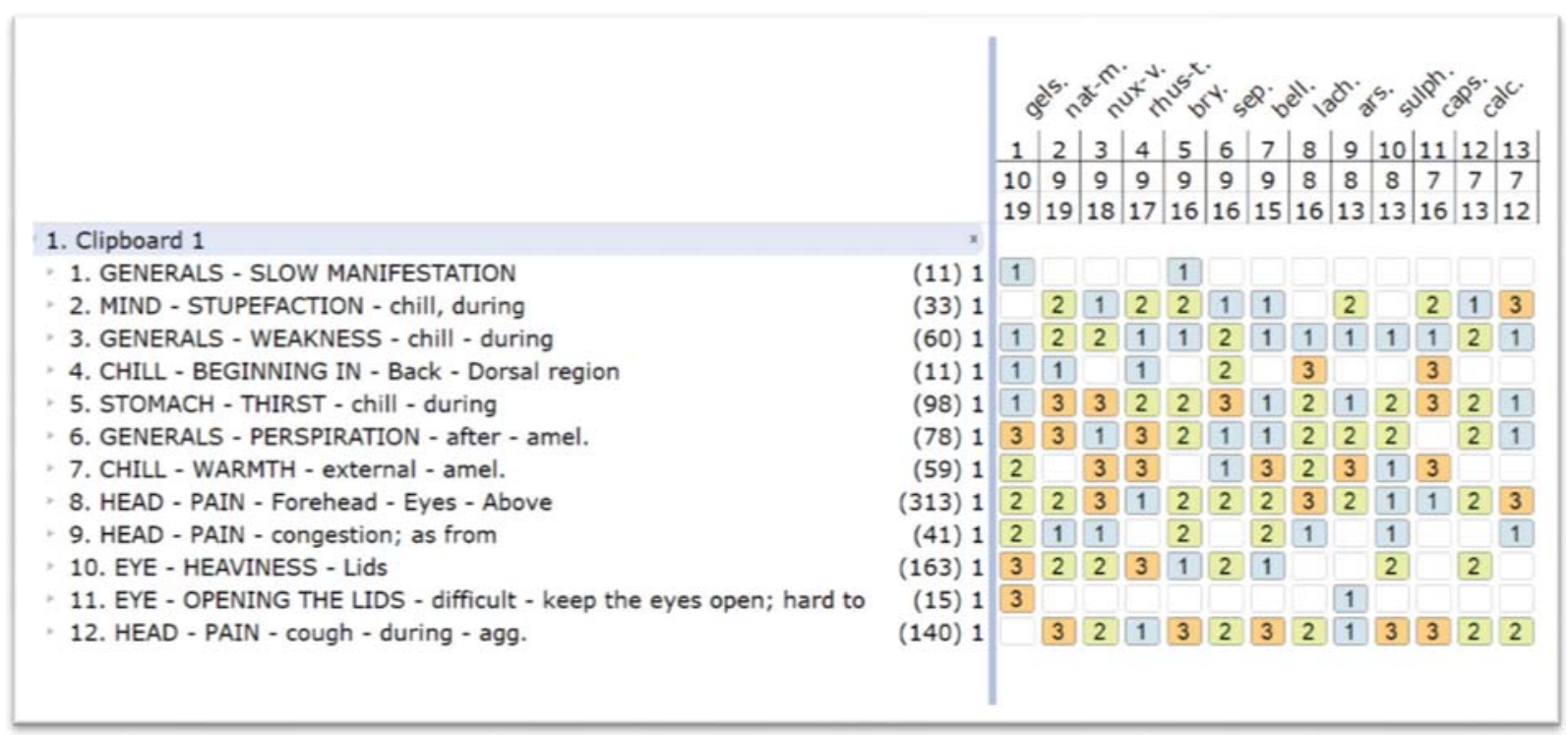

Fig. 9 Repertorization of Case HK4.2.

3. Nausea was aggravated by the smell of food.

4. Vomiting and diarrhea, aggravated by eating or drinking.

5. Nausea temporarily relieved after vomiting.

Arsenicum album 30C was prescribed, four times daily. The patient reported $50 \%$ improvement (score of 50 ) at 12 hours, and no more diarrhea within 24 hours; the patient was completely symptom free at day 3 . Repertorization is shown in - Fig. 10.

\section{Case HK4.4}

A 23-year-old man in the same cluster; a serology test, available 3 weeks after homeopathic treatment, was positive. His symptoms were categorized as mild. Generalized fatigue began around the same time as Case HK4.1, with similar progressive worsening for a few days, and treated with TCM before homeopathic consultation. The patient developed nasal symptoms, cough, and diarrhea gradually.
Homeopathic symptoms were:

1. No fever but prominent chills, which were mainly felt over the back.

2. Low appetite with no thirst.

3. Overwhelming fatigue with mental stupor, which ameliorated in open air.

4. Mild cough, associated with tickling in the throat.

5. Sneezing with moderate amount of burning discharge.

Gelsemium sempervirens $30 \mathrm{C}$ was prescribed, four times daily. The patient reported $20 \%$ improvement (score of 80 ) at 12 hours, and more than $80 \%$ improvement (score of 20) in 3 days. Repertorization is shown in - Fig. 11.

\section{Case HK4.5}

The patient was a 21-year-old man in the same cluster; a serology test, available 3 weeks after homeopathic treatment, was positive. He was categorized as having mild symptoms.

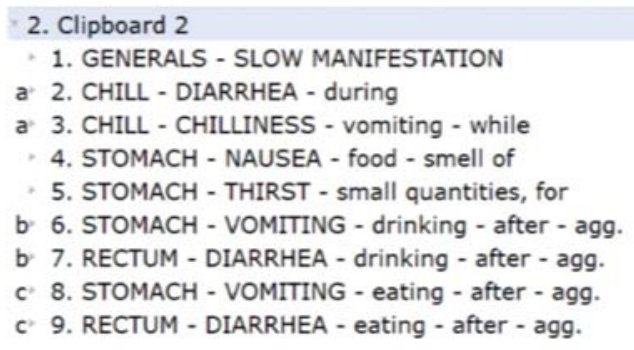

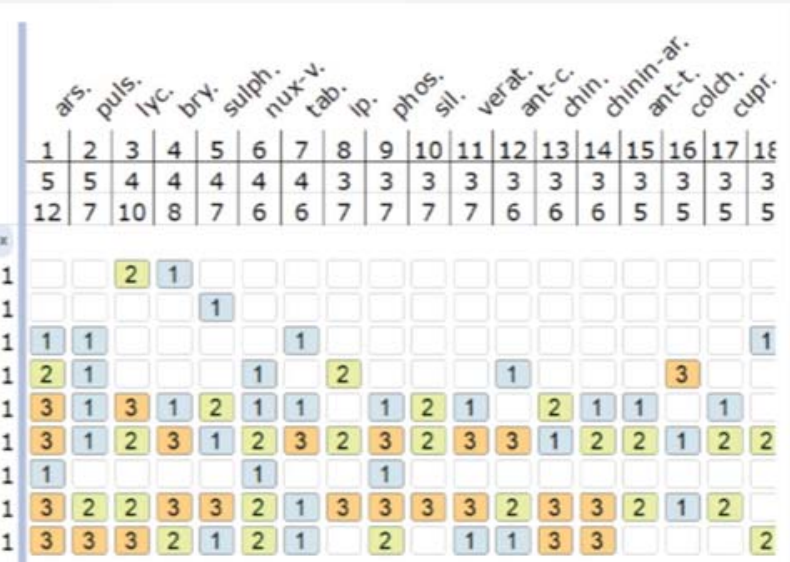

Fig. 10 Repertorization of Case HK4.3. 


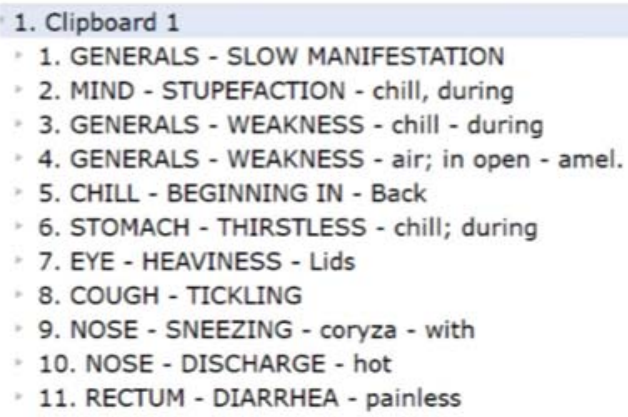

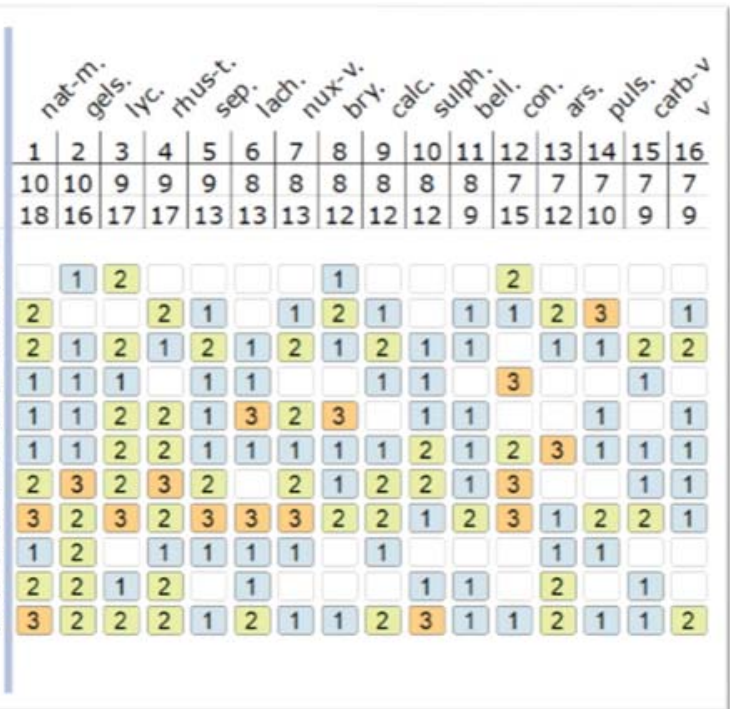

Fig. 11 Repertorization of Case HK4.4.

Generalized fatigue began around 6 to 7 days after the contact, and progressively worsened for 2 days; he was on TCM treatment before starting homeopathy. Homeopathic symptoms were:

1. No fever but severe chills; felt that chills ran up and down the spine. There was no myalgia.

2. No thirst during chills.

3. Overwhelming fatigue, with mental stupor.

4. Progressively worsening headache began from the leftside nape radiating to the left eyebrow.

5. Headache was relieved by $70 \%$ after profuse urination.

6. Heaviness was felt in the eyelids, which made him reluctant to keep his eyes open. The headache was associated with slight double vision.

7. Generally ameliorated by warmth and after perspiration.

Gelsemium sempervirens 30C, four times daily, was prescribed. The patient reported 50\% improvement (score of 50) at 12 hours, and was free of symptoms in 3 days. Repertorization is shown in - Fig. 12.

\section{Cluster no. 5}

\section{Case HK5.1}

The patient was a 23-year-old man; he was one of the patients in a cluster with at least one RT-PCR positive case diagnosed in February 2020; a serology test, available 2 weeks after homeopathic treatment, was positive. The patient was categorized as mild.

Generalized fatigue began 2 days after close contact with the index case in February 2020. He had progressively worsening headache and chills for 2 weeks, and was on TCM before homeopathy; cough was minimal. Homeopathic symptoms included:

1. No fever but worsening chills with headache.

2. Chills ran up and down the spine.

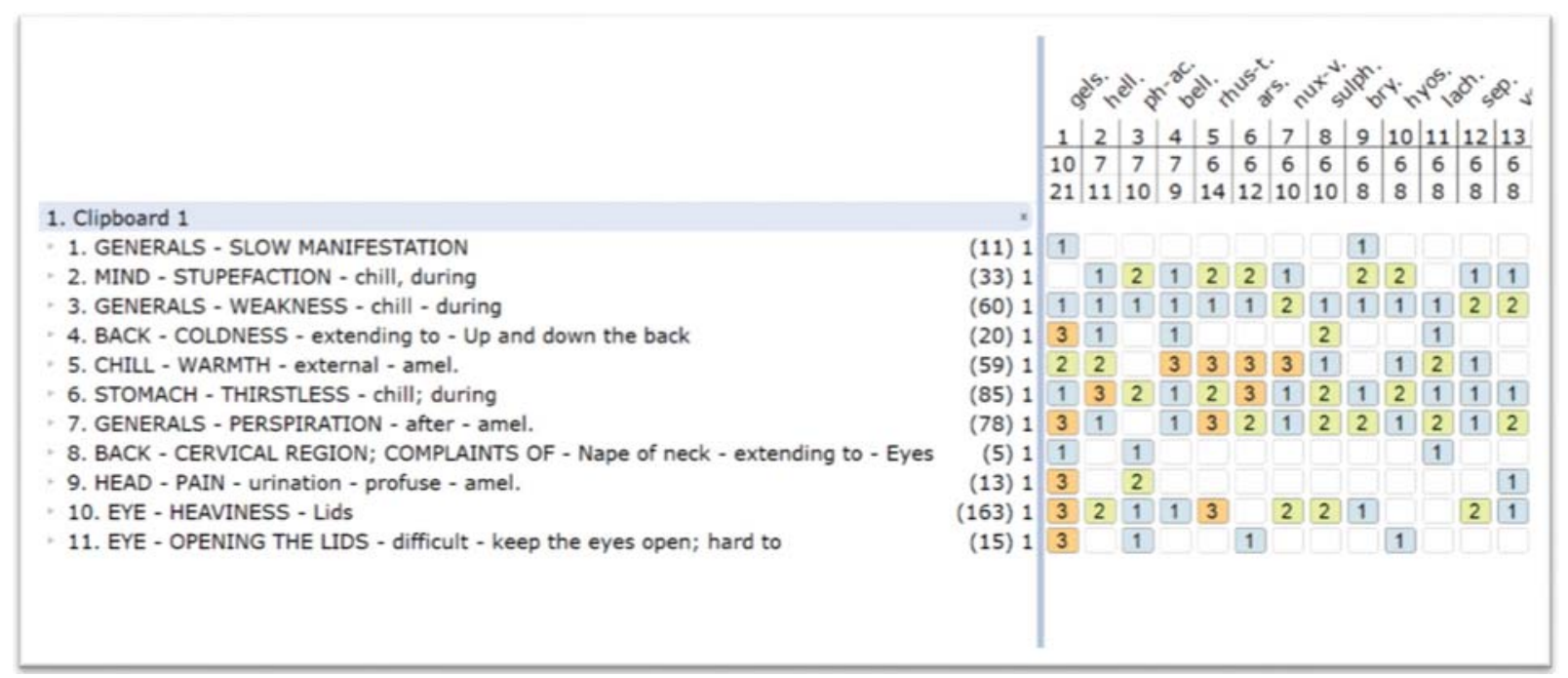

Fig. 12 Repertorization of Case HK4.5. 
1. Clipboard 1

1. GENERALS - SLOW MANIFESTATION

2. GENERALS - WEAKNESS - chill - during

3. MIND - STUPEFACTION - chill, during

4. STOMACH - THIRSTLESS - chill; during

5. BACK - COLDNESS - extending to - Up and down the back

6. GENERALS - WEATHER - cold weather - wet - agg.

7. HEAD - CONSTRICTION - band or hoop

8. EYE - HEAVINESS - Lids

9. EYE - OPENING THE LIDS - difficult - keep the eyes open; hard to

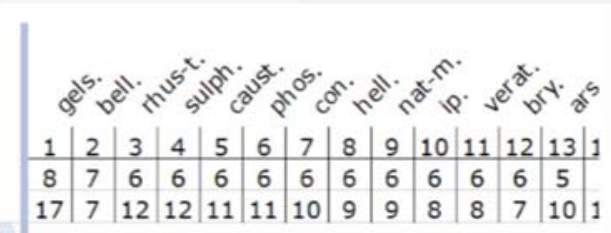

\begin{tabular}{ll|l|l|l|l|l|l|l|l|l|l|l|l|l|l|l|} 
(11) & 1 & 1 & & & & & & 2 & & & \\
(60) & 1 & 1 & 1 & 1 & 1 & 2 & 2 & & 1 & 2 & 1 & 2 & 1 & 1 \\
\hline
\end{tabular}

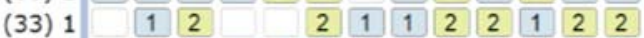

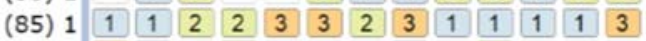

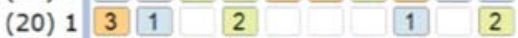

\begin{tabular}{ll|l|l|l|l|l|l|l|l|l|l|l|l|} 
(144) 1 & 2 & 1 & 3 & 2 & 1 & 1 & 1 & 1 & 1 & 2 & 1 & 3 \\
\hline
\end{tabular}

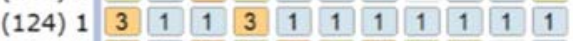

\begin{tabular}{ll|l|l|l|l|l|l|l|l|l|l|l|l|} 
(163) 1 & 3 & 1 & 3 & 2 & 3 & 2 & 3 & 2 & 2 & & 1 & 1
\end{tabular}

(15) 13

Fig. 13 Repertorization of Case HK5.1.

3. No thirst during chills.

4. Overwhelming fatigue with mental stupor.

5. Heaviness of the eyelids making it difficult for him to keep the eyes open.

6. Generally aggravated by cold and wet weather.

7. Headache described as "being tied by a band around the head".

8. No feeling of thirst during 3 days of chills.

Gelsemium sempervirens 30C, four times daily, was prescribed. The patient reported $90 \%$ improvement in headache at 12 hours, and $90 \%$ improvement (score of 10) in 3 days. Repertorization is shown in - Fig. 13.

\section{Case HK5.2}

The patient was a 24-year-old man in the same cluster as Case 5.1; his serology test, available 2 weeks after homeopathic treatment, was positive. His symptoms were categorized as mild.

Generalized fatigue, sleepiness, headache, and cough began 3 days after close contact with the index case, and developed into shortness of breath after taking some over-the-counter cough mixture. He was on TCM for 2 weeks, with persistent symptoms, before homeopathy. Homeopathic symptoms included:

1. No fever but chills. The chills were mainly in the back, running up and down the spine.

2. No thirst during chills.

3. Overwhelming fatigue was associated with pain from the nape of the neck radiating to the head, and the pain around the head was described as "constricting with a band".

4. Constrictive tightness in the chest.

5. Central chest pain aggravated by coughing.

6. Tickling in the throat.

7. Involuntary urination during cough.

8. Cough was mostly dry, except for some yellowish sputum produced upon waking up in the morning.

9. Dry cough aggravated at night, and after having sweet foods.
Gelsemium sempervirens 30C, four times daily, was prescribed. The patient reported $40 \%$ improvement (score of 60 ) at 12 hours, and $80 \%$ improvement (score of 20) in 3 days. Repertorization is shown in -Fig. 14.

\section{Case HK5.3}

The patient was a 23-year-old man in the same cluster as Case 5.1 ; a serology test, available 2 weeks after homeopathic treatment, was positive. The patient was categorized as a mild case.

Cough and fatigue began 7 days after close contact with the index case; he was on TCM for 2 weeks. Symptoms did not improve for 2 weeks before he started homeopathy. Homeopathic symptoms included:

1. Overwhelming tiredness and stupefying sleepiness.

2. Eyelids were heavy, with difficulty keeping the eyes open.

3. Emotionally dull; not irritable.

4. Cough was associated with pain in the central chest, tickling in the chest, and involuntary squirting of urine.

5. Mostly dry cough, except for some yellowish sputum produced upon waking up in the morning.

6. Dry cough aggravated during the night.

Gelsemium sempervirens 30C, four times daily, was prescribed. The patient reported $30 \%$ improvement (score of 70 ) at 12 hours, and $80 \%$ improvement (score of 20) in 3 days. Repertorization is shown in - Fig. 15.

\section{Case HK5.4}

The patient was a 22-year-old man in the same cluster as Case 5.1; a serology test, available 2 weeks after homeopathic treatment, was positive. The patient was categorized as a mild case.

Cough and fatigue began 5 days after close contact with the index case. Before receiving homeopathy, his symptoms had persisted for 2 weeks, during which he had tried TCM. Homeopathic symptoms included:

1. Overwhelming tiredness and stupefying sleepiness.

2. Eyelids were heavy, with difficulty keeping the eyes open. 
1. Clipboard 1

1. GENERALS - SLOW MANIFESTATION

2. GENERALS - WEAKNESS - chill - during

3. BACK - COLDNESS - extending to - Up and down the back

4. STOMACH - THIRSTLESS - chill; during

5. HEAD - CONSTRICTION - band or hoop

6. BACK - PAIN - Cervical region - Nape of neck - extending to - Head

7. CHEST - CONSTRICTION

8. CHEST - PAIN - cough - during - agg.

9. COUGH - TICKLING - Throat; in

10. BLADDER - URINATION - involuntary - cough agg.; during

11. COUGH - DRY - expectoration - morning, only in

12. COUGH - NIGHT

13. COUGH - SUGAR - agg
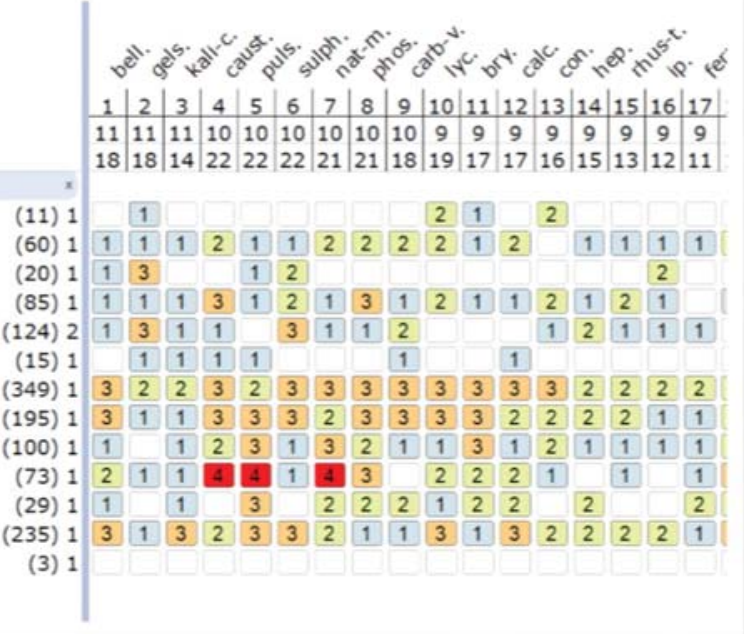

\begin{tabular}{|l|l|l|l|l|l|l|l|l|l|l|l|l|l|l|l|l|} 
(60) 1 & 1 & 1 & 1 & 2 & 1 & 1 & 2 & 2 & 2 & 2 & 1 & 2 & 1 & 1 & 1 & 1 \\
\hline
\end{tabular}

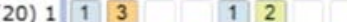

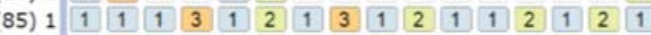

\begin{tabular}{l|l|l|l|l|l|l|l}
3 & 1 & 1 & 2 \\
\hline
\end{tabular}

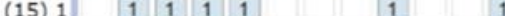

\begin{tabular}{|l|l|l|l|l|l|l|l|l|l|l|l|l|l|l|l|l|l|} 
(349) 1 & 3 & 2 & 2 & 3 & 2 & 3 & 3 & 3 & 3 & 3 & 3 & 3 & 3 & 2 & 2 & 2 & 2 \\
\hline
\end{tabular}

\begin{tabular}{|l|l|l|l|l|l|l|l|l|l|l|l|l|l|l|l|l|}
\hline & & &
\end{tabular}

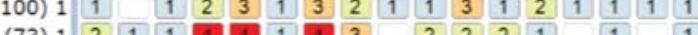

\begin{tabular}{|l|l|l|l|l|l|l|l|l|l|l|l|l|}
\hline (29) 1 & 1 & 1 & 3 & 2 & 2 & 2 & 1 & 2 & 2 & 2 & 2 \\
\hline
\end{tabular}

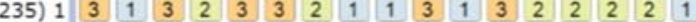

(3) 1

Fig. 14 Repertorization of Case HK5.2.

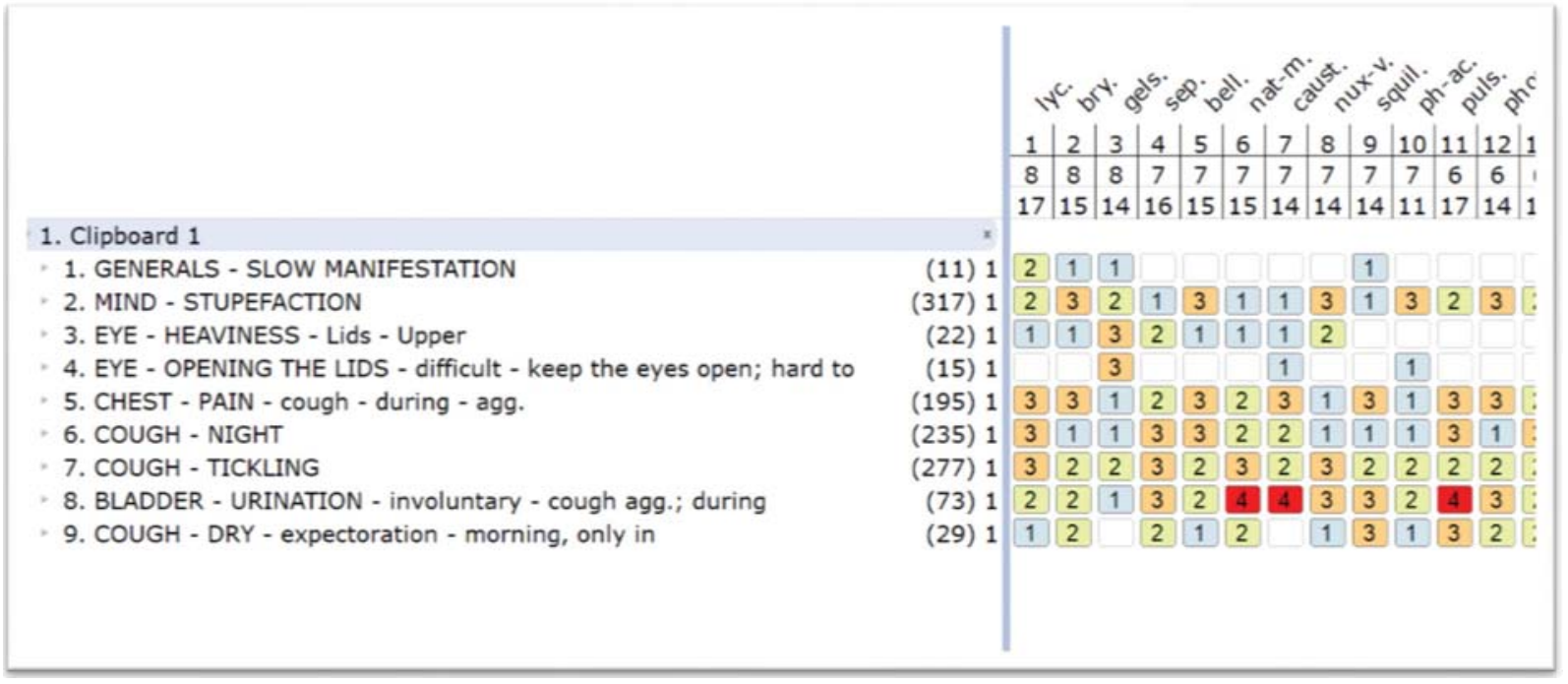

Fig. 15 Repertorization of Case HK5.3.

3. Generally aggravated from wet and cold weather.

4. Generally relieved after perspiration.

5. Cough was associated with pain in the central chest, tickling in the throat and chest, and involuntary squirting of urine.

6. The cough was dry most of the time.

Gelsemium sempervirens 30C, four times daily, was prescribed. The patient reported $30 \%$ improvement (score of 70) at 12 hours, and 70\% improvement (score of 30 ) in 3 days. Repertorization is shown in - Fig. 16.

\section{Case HK5.5}

A 23-year-old man in the same cluster as Case 5.1; a serology test, available 2 weeks after homeopathic treatment, was positive. The patient was categorized as a mild case.

Fever, severe myalgia, and cough began 6 days after close contact with the index case; symptoms did not improve with 3 days of TCM before starting homeopathy. Homeopathic symptoms included:
1. Fever 38.3 to $38.5^{\circ} \mathrm{C}$ for 3 days at consultation, alternating with chills.

2. No thirst during the fever or chills.

3. Weakness and severe bone pain during fever; back felt like it was broken, not aggravated or ameliorated with motion.

4. Cough was mild.

Eupatorium perfoliatum 30C, four times daily, was prescribed. The patient reported $30 \%$ improvement (score of 70) at 12 hours, and $80 \%$ improvement (score of 20 ) in 3 days. Repertorization is shown in - Fig. 17.

\section{Cluster no. 6}

\section{Case HK6.1}

The patient was a 49-year-old woman with past medical history of meningioma on conservative treatment. She was related to a cluster with one RT-PCR positive case diagnosed in March 2020. Her symptoms were categorized as mild. 


\section{Clipboard 1}

1. GENERALS - SLOW MANIFESTATION

2. MIND - STUPEFACTION

3. GENERALS - PERSPIRATION - after - amel.

4. GENERALS - WEATHER - cold weather - wet - agg.

5. EYE - HEAVINESS - Lids - Upper

6. EYE - OPENING THE LIDS - difficult - keep the eyes open; hard to

7. CHEST - PAIN - cough - during - agg.

8. COUGH - TICKLING

9. BLADDER - URINATION - involuntary - cough agg.; during

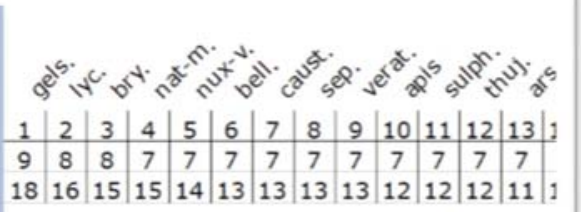

(11) $1 \quad 1 \quad 2 \quad 1$

\begin{tabular}{ll|l|l|l|l|l|l|l|l|l|l|l|l|l|} 
(317) 1 & 2 & 2 & 3 & 1 & 3 & 3 & 1 & 1 & 3 & 3 & 2 & 2 & 2 \\
\hline
\end{tabular}

\begin{tabular}{l|l|l|l|l|l|l|l|l|l|l|l|l|l|} 
(78) 1 & 3 & 1 & 2 & 3 & 1 & 1 & 1 & 2 & 1 & 2 & 2 & 2 \\
\hline
\end{tabular}

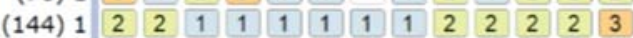

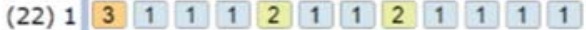

(15) 13

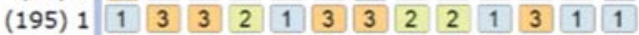

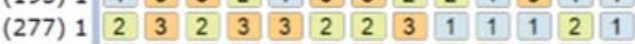

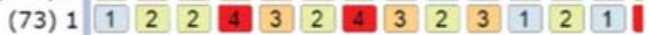

Fig. 16 Repertorization of Case HK5.4.

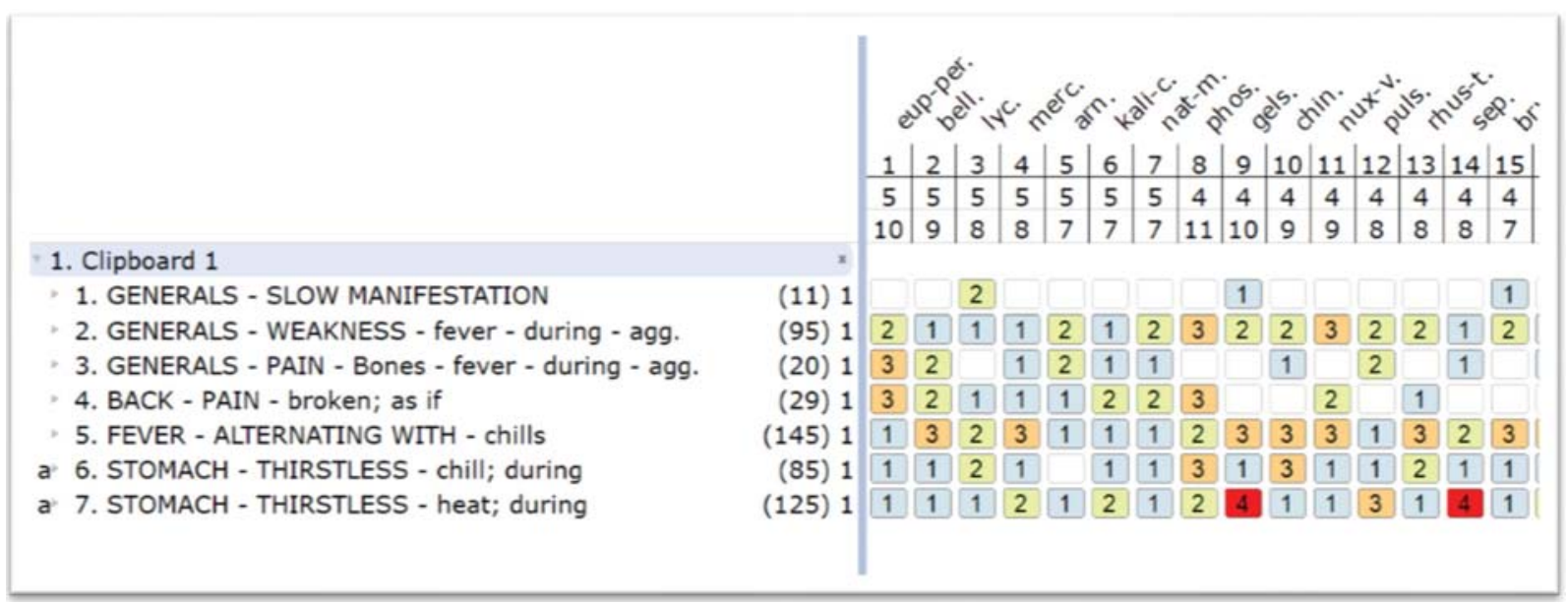

Fig. 17 Repertorization of Case HK5.5.

She had repeated close contact with the cluster since early March 2020, with worsening dry cough and shortness of breath for 2 weeks before she sought help from homeopathy. She refused any conventional or TCM treatment because of her previous sensitivity to these measures. The following homeopathic symptoms were found:

1. Slow onset and progression of symptoms.

2. No fever but chills; profound weakness and restlessness during chills.

3. Desire to be alone and not being bothered.

4. General aggravation from wet weather.

5. Obvious increase in thirst, with desire to drink warm water in large quantity.

6. Headache in the forehead above the eyes.

7. Difficulty keeping the eyes open.

8. Dry cough aggravated in the evening.

9. Dry cough aggravated after midnight, especially after 2 or 3 a.m.; must sit up to relieve.

10. Chest pain on coughing; needs to hold the chest with her hands.

11. Pain in the throat on coughing.
12. Cough, especially aggravated when she entered a warm room from open air.

13. Tickling in the throat.

14. Cough aggravated by talking.

15. Cough aggravated by deep breathing.

16. Cough ameliorated by drinking warm water.

17. Mainly dry cough, with minor expectoration only in the morning.

18. Cough associated with lachrymation.

19. Cough associated with involuntary urination.

20. Difficulty in breathing, aggravated during the night.

21. Constriction in the chest.

Bryonia alba 200C was prescribed, four times daily. Bryonia alba 200C was used instead of 30C because of the high intensity of her cough. The patient reported that symptoms improved by $50 \%$ within 15 minutes after the first dose, and perspiration followed and further improved. On the first day, she reported her symptoms as improved for 2.5 hours after each dose of the remedy, and therefore the dosage was increased to 2-hourly. She reported more than $60 \%$ (score of $<40$ ) improvement in symptoms at day 3. Repertorization is shown in - Fig. 18. 


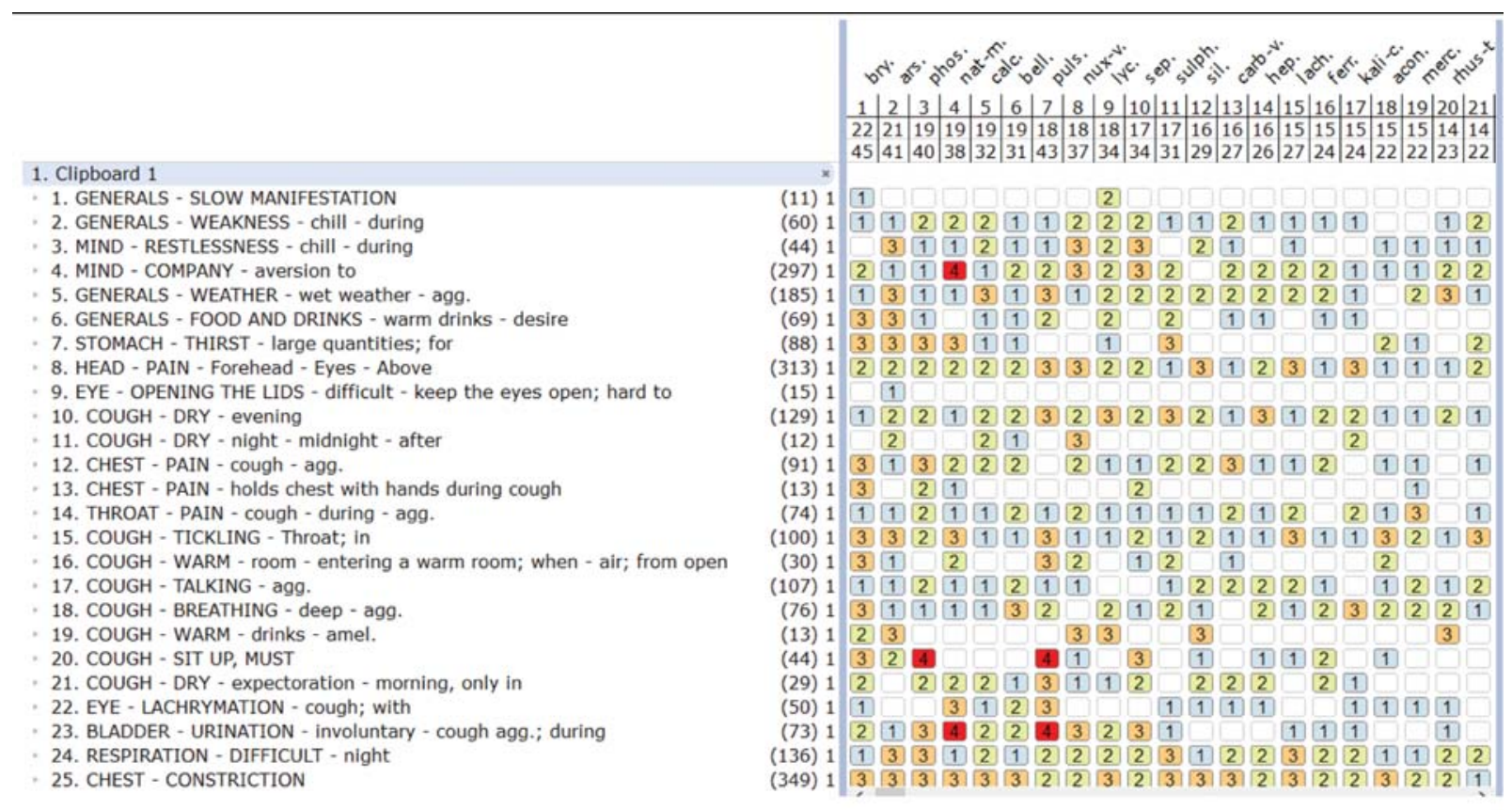

Fig. 18 Repertorization of Case HK6.1.

\section{Analysis}

The case series comprises 10 young men and 8 young/middleaged women, each with mild symptoms. The most frequently indicated medicines for the 18 cases were Gelsemium sempervirens $(n=12)$ and Bryonia alba $(n=4)$, followed by Eupatorium perfoliatum $(n=1)$ and Arsenicum album $(n=1)$. Gelsemium sempervirens was used in $80 \%$ of the cases in clusters 3, 4, and 5. Eighteen common symptoms with a minimum frequency of 4 were screened from 79 selected rubrics from all the cases and are summarized in - Table $\mathbf{1}$.

These common symptoms constructed the characteristic symptom pictures of the two commonly indicated medicines: Bryonia alba and Gelsemium sempervirens. It is known in the literature that Bryonia alba and Gelsemium sempervirens are related remedies: Bryonia alba is found to have good function when it is prescribed following the initial prescription of Gelsemium sempervirens. ${ }^{16}$

Frequencies of all common symptoms (present in $>2$ cases) in the four cases of Bryonia alba are summarized in -Table 2. And frequencies of all common symptoms (present in $>3$ cases) in the 12 cases of Gelsemium sempervirens are summarized in - Table 3.

Eight and seven differentiating homeopathic features were identified for Bryonia alba and Gelsemium sempervirens, respectively, shown with repertorization in - Tables 4 and 5 .

\section{Discussion}

This case series provides in detail the full repertorization of a few clusters in Hong Kong. More experience from other countries or regions will be helpful to find out if the homeopathic symptomatology pattern is consistent or not.
From the experience in Hong Kong, the homeopathic features of the patients who were categorized as mild were quite obvious and characteristic. Common symptoms of the disease, such as dry cough, fatigue, sore throat and shortness of breath, would not be very helpful in finding the simillimum because these symptoms are present in several homeopathic medicines. Homeopathic symptoms that were strange, rare, and peculiar in classical textbooks were readily visible at a higher frequency compared to times without the epidemic. Examples include the chills that went up and down the back, the band-like headache, and the relief of headache from profuse urination.

It is important to emphasize that no direct causation effect can be concluded from a case series which, by definition, was observational and non-controlled: the reported percentage improvements in symptoms should therefore be viewed accordingly. Other limitations of this case series include its small sample size and the lack of severe or critical COVID-19 cases; the majority of the cases in this series were young and all were categorized as mild. Information about homeopathic clinical features of the severe and critical cases would be very useful for homeopaths around the world. However, more than $80 \%$ of all confirmed COVID-19 cases have been categorized as mild or moderate. ${ }^{17}$ These were the patients with relatively good past health compared to the severe or critical patients, who often suffered from chronic co-morbidities. ${ }^{18} \mathrm{Dr}$. Hahnemann stated in The Organon that the remedies identified from the peculiar and uniform characteristics of patients in the same outbreak would be consistently serviceable in the epidemic for people with good past health ( 2241$)$. In other words, Hahnemann observed more than 200 years ago that the relatively healthy patients showed a more homogeneous homeopathic clinical picture in epidemics, so that 
Table 1 Homeopathic rubrics with a minimum frequency of 4 in the 18 cases

\begin{tabular}{|c|c|c|}
\hline & Rubrics & Frequency \\
\hline 1 & Generals-Slow manifestation & 18 \\
\hline 2 & $\begin{array}{l}\text { Mind-Stupefaction } \\
\text { Mind-Stupefaction-chill, during } \\
\text { Mind-Stupefaction-fever, during }\end{array}$ & 12 \\
\hline 3 & $\begin{array}{l}\text { Generals-Weakness-chill, during } \\
\text { Generals-Weakness-fever, during }\end{array}$ & 12 \\
\hline 4 & $\begin{array}{l}\text { Eye-Heaviness-lids } \\
\text { Eye-Opening the lids-difficult- } \\
\text { keep the eyes open; hard to }\end{array}$ & 11 \\
\hline 5 & $\begin{array}{l}\text { Cough-Tickling } \\
\text { Cough-Tickling-throat; in } \\
\text { Cough-Tickling-Chest }\end{array}$ & 10 \\
\hline 6 & $\begin{array}{l}\text { Stomach-Thirstless-chill; during } \\
\text { Stomach-Thirstless-fever; during }\end{array}$ & 10 \\
\hline 7 & $\begin{array}{l}\text { Chill-Beginning in back } \\
\text { Chill-Beginning in-back-dorsal } \\
\text { region } \\
\text { Back-Coldness-extending to-Up } \\
\text { and down the back }\end{array}$ & 10 \\
\hline 8 & $\begin{array}{l}\text { Bladde-Urination-involuntary- } \\
\text { cough agg.; during }\end{array}$ & 8 \\
\hline 9 & $\begin{array}{l}\text { General-Weather-cold weather- } \\
\text { wet-agg. } \\
\text { General-Weather-wet-agg. }\end{array}$ & 8 \\
\hline 10 & Head-Constriction-band or hoop & 7 \\
\hline 11 & $\begin{array}{l}\text { Cough-Night } \\
\text { Cough-Night-midnight-after } \\
\text { Cough-Dry-night-midnight-after }\end{array}$ & 7 \\
\hline 12 & $\begin{array}{l}\text { Back-Pain-Cervical region-Nape of } \\
\text { neck-extending to-head }\end{array}$ & 6 \\
\hline 13 & Chest- Pain-cough-during-agg. & 6 \\
\hline 14 & Head-Pain-cough-during-agg. & 5 \\
\hline 15 & $\begin{array}{l}\text { Head-Pain-urination-profuse- } \\
\text { amel. }\end{array}$ & 5 \\
\hline 16 & Stomach-Thirst-large quantities; for & 4 \\
\hline 17 & $\begin{array}{l}\text { Cough-Dry-expectoration- } \\
\text { morning, only in }\end{array}$ & 4 \\
\hline 18 & Generals-Perspiration-after-amel. & 4 \\
\hline
\end{tabular}

the few remedies identified from case series could be applicable in most patients according to the Law of Similars. Thus, by identifying the homeopathic clinical features in the mild COVID-19 patients, the peculiar characteristic of the epidemic in the region should be revealed. In severe and critical cases, a more individualized pattern of homeopathic symptoms would be expected because of their co-existing constitutional susceptibilities.

\section{Conclusion}

The 18 mild COVID-19 cases in Hong Kong presented two main sets of homeopathic symptom pictures, indicating
Table 2 Homeopathic rubrics with a minimum frequency of 3 in the 4 cases of Bryonia alba

\begin{tabular}{|l|l|l|}
\hline & Rubrics & Frequency \\
\hline 1 & Generals-Slow manifestation & 4 \\
\hline 2 & Stomach-Thirst-large quantities; for & 4 \\
\hline 3 & $\begin{array}{l}\text { Cough-Tickling } \\
\text { Cough-Tickling-throat; in } \\
\text { Cough-Tickling-Chest }\end{array}$ & 4 \\
\hline 4 & Mind-Company-Aversion to & 3 \\
\hline 5 & $\begin{array}{l}\text { Generals-Food and Drinks-warm } \\
\text { drinks-desire }\end{array}$ & 3 \\
\hline 6 & $\begin{array}{l}\text { Generals-Pain-Bones } \\
\text { Generals-Pain-Bones-chill; during } \\
\text { Generals-Pain-Bones-fever; during }\end{array}$ & 3 \\
\hline 7 & Head-Pain-cough-during-agg. & 3 \\
\hline 8 & Throat-Pain-cough-during-agg. & 3 \\
\hline 9 & Cough-Warm-drinks-amel. & 3 \\
\hline 10 & $\begin{array}{l}\text { Cough-Lying-agg. } \\
\text { Cough-Sit up, must }\end{array}$ & 3 \\
\hline
\end{tabular}

Table 3 Homeopathic rubrics with a minimum frequency of 4 in the 12 cases of Gelsemium sempervirens

\begin{tabular}{|c|c|c|}
\hline & Rubrics & Frequency \\
\hline 1 & Generals-Slow manifestation & 12 \\
\hline 2 & $\begin{array}{l}\text { Mind-Stupefaction } \\
\text { Mind-Stupefaction-chill, during } \\
\text { Mind-Stupefaction-fever, during }\end{array}$ & 11 \\
\hline 3 & $\begin{array}{l}\text { Eye-Heaviness-lids } \\
\text { Eye-Opening the lids-difficult-keep } \\
\text { the eyes open; hard to }\end{array}$ & 9 \\
\hline 4 & $\begin{array}{l}\text { Generals-Weakness-chill, during } \\
\text { Generals-Weakness-fever, during }\end{array}$ & 9 \\
\hline 5 & $\begin{array}{l}\text { Chill-Beginning in back } \\
\text { Chill-Beginning in-back-dorsal } \\
\text { region } \\
\text { Back-Coldness-extending to-Up and } \\
\text { down the back }\end{array}$ & 9 \\
\hline 6 & $\begin{array}{l}\text { Stomach-Thirstless-chill; during } \\
\text { Stomach-Thirstless-fever; during }\end{array}$ & 9 \\
\hline 7 & $\begin{array}{l}\text { Cough-Tickling } \\
\text { Cough-Tickling-throat; in } \\
\text { Cough-Tickling-Chest }\end{array}$ & 6 \\
\hline 8 & $\begin{array}{l}\text { Head-Constriction-band or hoop } \\
\text { Head-Pain-pressing pain-band as } \\
\text { from a }\end{array}$ & 6 \\
\hline 9 & $\begin{array}{l}\text { General-Weather-cold weather- } \\
\text { wet-agg. } \\
\text { General-Weather-wet weather-agg. }\end{array}$ & 6 \\
\hline 10 & $\begin{array}{l}\text { Cough-Night } \\
\text { Cough-Night-midnight-after } \\
\text { Cough-Dry-night-midnight-after }\end{array}$ & 6 \\
\hline 11 & & 6 \\
\hline
\end{tabular}


4 National Health Commission of the People's Republic of China. Press conference of the joint prevention and control mechanism of the state council; February 17, 2020. Available at: http:// www.gov.cn/xinwen/gwylflkjz18/index.htm. Accessed April 8, 2020

5 Luo H, Tang QL, Shang YX, et al. Can Chinese medicine be used for prevention of corona virus disease 2019 (COVID-19)? A review of historical classics, research evidence and current prevention programs. Chin J Integr Med 2020;26:243-250

6 Jacobs J. Homeopathic prevention and management of epidemic diseases. Homeopathy 2018;107:157-160

7 Hahnemann S. Heilung und Verhütung des Scharlachfiebers. Gotha, Germany 1801

8 Winston J. The Faces of Homeopathy. Wellington, New Zealand: Great Auk Publishing; 1999

9 Wadhwani GG. Homeopathic drug therapy. Homeopathy in chikungunya fever and post-chikungunya chronic arthritis: an observational study. Homeopathy 2013;102:193-198

10 Nair KRJ, Gopinadhan S, Kurup TNS, et al. Homoeopathic genus Epidemicus 'Bryonia alba' as a prophylactic during an outbreak of Chikungunya in India: a cluster-randomised, double-blind, placebo- controlled trial. Indian J Res Homoeopathy 2014; 8:160-165

11 Saeed-ul-Hassan S, Tariq I, Khalid A, Karim S. Comparative clinical study on the effectiveness of homeopathic combination remedy with standard maintenance therapy for dengue fever. Trop J Pharm Res 2013;12:767-770

12 Jacobs J, Fernandez EA, Merizalde B, Avila-Montes GA, Crothers D. The use of homeopathic combination remedy for dengue fever symptoms: a pilot RCT in Honduras. Homeopathy 2007;96:22-26

13 Bracho G, Varela E, Fernández R, et al. Large-scale application of highly-diluted bacteria for leptospirosis epidemic control. Homeopathy 2010;99:156-166

14 Van Erp VMA, Brands M. Homoeopathic treatment of malaria in Ghana. Br Homeopath J 1996;85:66-70

15 Diagnosis and Treatment Protocol for COVID-19 (Trial Version 7), National Health Commission of the People's Republic of China. Available at: http://www.nhc.gov.cn/xcs/zhengcwj/202003/ 46c9294a7dfe4cef80dc7f5912eb1989.shtml. Accessed April 8, 2020

16 Schroyens F. Related Remedy, RadarOpus database 2007. Available at: https://www.radaropus.com/academy/Radaropus-in-der-t\% C3\%A4glichen-Praxis-Webinar-mit-Dr.-Frederik-Schroyens

$17 \mathrm{Wu} \mathrm{Z}$, McGoogan JM. Characteristics of and important lessons from the coronavirus disease 2019 (COVID-19) outbreak in China: summary of a report of 72314 cases from the Chinese Center for Disease Control and Prevention. JAMA 2020;323:1239-1242

18 Guan WJ, Liang WH, Zhao Y. China Medical Treatment Expert Group for Covid-19. Comorbidity and its impact on 1590 patients with Covid-19 in China: a nationwide analysis. Eur Respir J 2020; $55: 2000547$ 